\title{
Rheum ribes Özütlerinin Antioksidan ve Antibakteriyel Aktiviteleri
}

\author{
Hatice Aysun MERCIMEK TAKCI ${ }^{1 *}$, Filiz UÇAN TÜRKMEN², Mustafa GÜNEŞ ${ }^{3}$, Pemra $^{2}$ \\ BAKIRHAN $^{4}$
}

\section{$\ddot{\mathbf{O z}}$}

Polygonaceae familyasının türü olan Rheum ribes'in taze gövde ve yaprakları Lübnan, İran ve Türkiye'nin doğusunda sebze olarak tüketilmektedir. Son zamanlarda farmakolojik alanlarda kullanılan bu bitkiden Asya ülkelerinde saf ilaç materyalleri üretilmektedir. Çalışmamızda, Rheum ribes gövde kısımlarından etil asetat, hekzan, metanol ve saf su çözücüleri kullanılarak 10-100 mg/mL konsantrasyonlarda hazırlanan özütlerin in vitro fitokimyasal, antioksidan ve antibakteriyel aktiviteleri incelenmiştir. Çözücülere bağlı olarak ekstraksiyon verimi değişmekle birlikte en yüksek ekstraksiyon verimi (\%25.3), en yüksek total fenolik $(0.80 \pm 0.00 \mathrm{mg} \mathrm{GAE} / \mathrm{g})$ ve flavonoid içerik $(0.321 \pm 0.00 \mathrm{mg} \mathrm{RE} / \mathrm{g})$ $100 \mathrm{mg} / \mathrm{mL}$ konsantrasyonda metanol özütünde belirlenmiştir. Rheum ribes metanol gövde özütünün $\mathrm{DPPH} \cdot$ süpürme aktivitesi \%91.10 \pm 0.51 olarak kaydedilmiş olup IC50 dozu $10.50 \mathrm{mg} / \mathrm{mL}$ 'dir. En yüksek Fe(II) iyonlarını şelatlama aktivitesi \%49.70 \pm 3.10 , indirgeme kapasitesi $(0.19 \pm 0.00)$ ve süperoksit anyonu giderme aktivitesi $(\% 39.20 \pm 2.40) 100$ $\mathrm{mg} / \mathrm{mL}$ konsantrasyonda metanol özütünde belirlenmiştir. Rheum ribes'in etil asetat, hekzan ve metanol özütlerinin test bakterileri üzerinde antibakteriyel aktivite gösteremediği belirlenmiştir. Saf su özütünün gösterdiği antibakteriyel aktivite $9.00 \pm 1.00$ ve $14.50 \pm 1.50 \mathrm{~mm}$ zon çapı aralığındadır. En yüksek inhibitör etki $14.50 \pm 1.50 \mathrm{~mm}$ zon çapı ile $S$. aureus'a karş1 gözlenmiştir.

Anahtar Kelimeler: Rheum ribes, Antioksidan, Antibakteriyel

\section{Antibacterial and Antioxidant Activities of Rheum ribes extracts}

\begin{abstract}
The fresh stem and leaves Rheum ribes, species of Polygonaceae family, are consumed as vegetable in Lebanon, Iran and eastern Turkey. Recently, crude drug materials from this plant are used in pharmacological research in Asian countries. In this study, in vitro phytochemical, antioxidant and antibacterial activity of the extracts prepared at $10-100 \mathrm{mg} / \mathrm{mL}$ concentrations by using ethyl acetate, hexane, methanol and distilled water from stem parts of Rheum ribes were examined. The extraction efficiency varies depending on the solvents and the highest extraction efficiency was calculated as $\% 25.3$ at methanol extract. The highest total phenolic and flavonoid contents were determined $0.80 \pm 0.00 \mathrm{mg} \mathrm{GAE} / \mathrm{g}$ and $0.321 \pm 0.00 \mathrm{mg} \mathrm{RE} / \mathrm{g}$ at $100 \mathrm{mg} / \mathrm{mL}$ concentration of methanolic extract. DPPH radical scavenging activity of methanolic stem extract was $\% 91.10 \pm 0.51$ (IC50 dose $10.50 \mathrm{mg} / \mathrm{mL}$ ). The highest $\mathrm{Fe}(\mathrm{II})$ ions chelating activity $(49.70 \pm 3.10 \%)$, reduction capacity $(0.19 \pm 0.00)$ and superoxide anion scavenging activity $(39.20 \pm 2.40 \%)$ were recorded at methanol extract. Ethyl acetate, hexane and methanol extracts of Rheum ribes not showed antibacterial activity against test bacteria. Antibacterial activity of distilled water extract was in the range of $9.00 \pm 1.00$ and $14.50 \pm 1.50 \mathrm{~mm}$. The highest inhibitory effect was observed against $S$. aureus with $14.5 \pm 1.50 \mathrm{~mm}$ zone diameter.
\end{abstract}

Keywords: Rheum ribes, Antioxidant, Antibacterial

${ }^{1}$ Kilis 7 Aralık Üniversitesi, Fen Edebiyat Fakültesi, Moleküler Biyoloji ve Genetik Bölümü, Kilis, Türkiye, mersimek@hotmail.com
${ }^{2}$ Kilis 7 Aralı Üniversitesi, Fen Edebiyat Fakültesi, Moleküler Biyoloji ve Genetik Bölümü, Kilis, Türkiye, ucanfiliz@gmail.com
${ }^{3}$ Kilis 7 Aralı Üniversitesi, Fen Bilimleri Enstitüsü, Moleküler Biyoloji ve Genetik ABD, Kilis, Türkiye, mstfgns79@gmail.com
${ }^{4}$ Kilis 7 Aralık Üniversitesi, Fen Bilimleri Enstitüsü, Moleküler Biyoloji ve Genetik ABD, Kilis, Türkiye, pemrabakirhan@gmail.com 


\section{Giriş}

Dünya Sağlık Örgütü küresel nüfusun \%80'inin birinci basamak sağl1k hizmeti ihtiyaçları için geleneksel yöntemlerle tıbbi bitkilerden elde edilen ilaçların kullanıldığını bildirmiştir. Tarih boyunca Anadolu'da da tedavi amaçlı kullanılan bitkilere, halk hekimliği uygulamalarında yaygın olarak rastlanılmaktadır. Anadolu'da yetişen bitkiler baharat, boya, gıda, çay, hayvan hastalıklarının tedavisi, meşrubat ve kozmetik sanayinde kullanımı gibi birçok alanda kültürel çeşitliliğimizin bir parçası olmuştur.

Yayla muzu (R. ribes), Lübnan, Irak, İran ve Türkiye'nin Doğu Anadolu Bölgelerinde yetişen Polygonaceae familyasına ait çok yıllık bir bitkidir (Davis, 1967). Doğu bölgelerimizde 1800 ile 2800 metre yüksekliklerde yayılış gösteren bitki olup, bölgesel olarak değişmekle beraber 1şgın, yayla muzu ve uçkun gibi adlarla anılmaktadır (Tosun ve Kızılay, 2003). R. ribes, Doğu Anadolu Bölgesinde Nisan, Mayıs ve Haziran aylarında görülüp, boyu ortalama $150 \mathrm{~cm}$ 'dir (Andiç ve ark., 2009). Gövde taban kısımdan yapraklıdır. Yaprakları büyük, kırmızımsı, bitkinin kenarları ince tırtırlı ve buruşuk şeklindedir. Yaprakların üst tarafı sert ve pürüzlüdür. Çiçekleri ise küçük, sarımsı ve beyazdır. Tohumların boyutu 9-15 mm'dir. Kazık köklü ve çok yıllıktır. R. ribes, kabukları gövdeden temizlenerek yenen, $\mathrm{pH}$ değeri 3.56 olması sebebiyle ekşi tat veren ve yeşil renkli bir bitkidir.

$R$. ribes 1939 yılında tıbbı açıdan ilk kez incelenmiştir. $R$. ribes yetiştiği bölgede halk tarafından gövde kısmı, taze iken dış kabuğu soyularak yenilmekle beraber Hakkâri'de uçkunlu dondurma ve kek olarak Bitlis’te turşusu yapılarak tüketilmektedir. Tunceli ve Bitlis'in bazı bölgelerinde ateşte pişirilerek tüketilmektedir (Güvenç ve Kaya, 1996).

Besin olarak tüketilmekle beraber halk arasında tıbbi amaçlı olarak da kullanımı yetiştiği bölge içinde oldukça yaygındır. Bitlis ve çevresinde bitkinin gövde kısmı sindirimi kolaylaştırıcı olarak bilinmekte, kök kısımları ise hemoroit ve şeker hastalığı tedavisi için de kullanılmaktadır. Aynı zamanda kökleri, şeker hastalığında fayda sağlamış, ülser ve mide rahatsızlığında olumlu etkiye rastlanmıştır (Tosun ve Kızılay, 2003; Meral 2017). R. ribes kökünde anti tümör etkiye sahip maddelerin olduğu düşünülmektedir (Mohammed ve Karim, 2010). Antioksidan özelliklerinden dolayı kanserli hücrelere etki yönünden olumlu sonuçlar verebileceği düşünülen bu bitki üzerinde yapılan bir çalışmada ilk bulgulara göre kaynatarak elde edilen özütlerin kanserli dokuda antiproliferatif bir etkisi bulunamamıştır. $R$. ribes genç sürgünlerinde, krizofanol, fiskiyon ve emodolan trakinonlarıyla, kuersetin, 5-dezoksikuersetin, kuersetin 3-O-ramnozit, kuersetin 3-Ogalaktozit ve kuersetin 3-O-rutinozit flavonoidleri bulunmaktadır (Tosun ve Kızılay, 2003).

$\mathrm{Bu}$ çalışmada, aktarlardan temin edilen hazır kurutulmuş $R$. ribes'in gövde özütlerinin fitokimyasal özellikleri ve antibakteriyel aktivitelerinin incelenmesi amaçlanmıştır. 


\section{Materyal ve Metot}

\subsection{Bitki Özütlerinin Hazırlanması}

Aktarlardan temin edilen hazır kurutulmuş $R$. ribes'in gövde kısımları mekanik karıştırıcıda çekilerek toz haline getirilip kapalı bir kap içerisinde oda sıcaklığında saklanmıştır. \%10 (w/v) konsantrasyonda etil asetat, hekzan, metanol ve saf su kullanılarak oda sıcaklığında 180 rpm'de 72 saat çalkalamalı koşullarda ekstrakte edilmiştir. Ekstraksiyonu takiben süzüntü Whatman filter paper No.1 ile süzülmüş ve evaporatörde (Heidolph Hei-Vap Presicion ML/G1) konsantre edilmiştir. Her çözücünün kaynama noktasına uygun sıcaklıklarda yapılan evaporasyon sonrası örneklerin son konsantrasyonu $100 \mathrm{mg} / \mathrm{mL}$ olacak şekilde metanol içerisinde süspanse edilmiştir. Özütler analizlerde kullanılana kadar $+4^{\circ} \mathrm{C}$ 'de saklanmıştır.

\subsection{Fitokimyasal Analizler}

R. ribes özütlerindeki toplam fenolik madde miktarı Folin Ciocalteu kalorimetrik metodu ile belirlenmiştir. Ekstraktların $500 \mu \mathrm{L}$ 'sine \%7.5'lik $\mathrm{NaHCO}_{3}$ çözeltisinden $2.5 \mathrm{~mL}$ eklenmiştir. Karışıma \%10'luk Folin-Ciocalteu ayracından $2.5 \mathrm{~mL}$ ilave edilmiştir. $45^{\circ} \mathrm{C}$ 'de 45 dak. su banyosunda inkübasyon süresince tüplerdeki renk değişimi takip edilmiştir. Örneklerin absorbansı spektrofotometrede (Biochrom, Libra S60, B, England) $765 \mathrm{~nm}$ dalga boyunda köre karş1 okutulmuştur. Sonuçlar, ekstrenin gramı başına mg gallik asit eşdeğeri (GAE) olarak ifade edilmiştir (Stankovic, 2011).

Flavonoid madde miktarı için, özütler 1:5 oranda saf su ile seyreltilmiş ve $\% 5^{\prime}$ lik $300 \mu \mathrm{L}$ $\mathrm{NaNO}_{2}$ eklenerek oda sıcaklığında 5 dak. bekletilmiştir. Takiben reaksiyon karışımına $600 \mu \mathrm{L}$ \%10'luk $\mathrm{AlCl}_{3} \cdot 6 \mathrm{H}_{2} \mathrm{O}$ eklenmiş tekrar 5 dak. oda sıcaklığında bekletilmiştir. $2 \mathrm{~mL} 1 \mathrm{M}$ 'lık NaOH ilave edilmiş ve karışıma saf su eklenerek son hacim 10 mL'ye tamamlanmıştır. 510 nm'de karışımın absorbansı okutulmuştur. Sonuçlar, ekstrenin gramı başına mg rutin eşdeğeri (RE) olarak ifade edilmiştir. (Sharm ve Vig, 2013).

\subsection{Antioksidan Kapasite Analizleri}

DPPH· süpürme aktivite tayini: Blois'in (1958) tarafından bildirilen serbest radikal giderme metodu örneklerin bir elektron veya proton verebilme yeteneğine bağlı olarak DPPH· (1,1-difenil-2pikrilhidrazil) çözeltisinin renginin açılması esasına dayanmaktadır. 
Rheum özütlerinin $100 \mu \mathrm{L}$ 'si metanol içinde çözünmüş DPPH· $(0.025 \mathrm{~g} / \mathrm{L})$ çözeltisinin 3.9 mL'sine eklenmiştir. Reaksiyon gerçekleşmesi için karışım 120 dak. karanlıkta bekletilmiştir. Reaksiyon karışımı 515 nm dalga boyunda okutulmuştur. Standart olarak 200-1000 $\mu \mathrm{g} / \mathrm{mL}$ konsantrasyonda BHT (Butilhidroksi toluen) kullanılmıştır. Örnek yerine metanolün ilave edildiği tüplerin absorbansı kontrol olarak değerlendirilmiştir. Özütlerin DPPH· radikali giderme aktivitesi aşağıdaki formüle göre hesaplanmıştır.

$\mathrm{DPPH} \cdot$ inhibisyonu $(\%)=\left[\left(\mathrm{AbsKontrol}_{-} \mathrm{Abs}_{\text {Numune }}\right) / \mathrm{AbsKontrol}\right] \times 100$

Demir (II) iyonlarını şelatlama aktivitesinin tayini: Rheum özütlerinin $\mathrm{Fe}^{+2}$ iyonlarını şelatlama aktivitelerini belirlemek için Dinis ve ark., (1994) buldukları metot uygulanmıştır. Belirtilen yönteme göre demir şelatlama gücü yüksek olan ferrozinle, ekstraktlarda bulunan metal bağlayıcı bileşiklerin yarışması esasına dayanmaktadır. Özütler içinde bulunan bileşiklerin demir bağlama gücü yüksekse kırımızı renkli olan ferrozin-Fe ${ }^{+2}$ kompleksinin oluşumu engellenecektir.

$100 \mu \mathrm{L}$ özüt içeren deney tüplerine $370 \mu \mathrm{L}$ saf su ve $10 \mu \mathrm{L} 2 \mathrm{mM} \mathrm{FeCl}_{2}$ çözeltisi eklenmiştir. Reaksiyon karışımı oda sıcaklığında 30 dak. bekletilmiştir. Tüplere $20 \mu \mathrm{L} 5 \mathrm{mM}$ ferrozin çözeltisi ilave edilip karıştırılmıştır. Karışıma $2.5 \mathrm{~mL}$ saf su eklenerek 10 dak. bekletilmiştir. İnkübasyonu takiben spektrofotometrede $562 \mathrm{~nm}$ dalga boyunda köre karşılık örnekler okunmuştur. Standart olarak 50-250 $\mu \mathrm{g} / \mathrm{mL}$ konsantrasyonlarda EDTA kullanılmıştır. Örnek yerine özütlerin hazırlandığ çözücüye göre $1 \mathrm{~mL}$ saf su ve metanol kullanılarak kontrol çalışılmıştır. Ferrozin-Fe ${ }^{+2}$ kompleksinin inhibisyon yüzdesi aşağıda belirtilen formülle hesaplanmıştır.

\% Şelatlama Aktivitesi: (1-(562 nm'de Örnek Absorbans1/562 nm'de Kontrol Absorbans1)) x 100

İndirgeme kapasite tayini: Oyaizu'nın (1986) belirlediği metotla özütlerin indirgeme kapasitesi belirlenmiştir. Örneklerin içinde bulunan indirgen maddenin $\mathrm{Fe}^{+3}$ iyonunu $\mathrm{Fe}^{+2}$ iyonuna indirgenmesi test edilmektedir. Ortama $\mathrm{FeCl}_{3}$ eklenmesiyle Prusya mavisi rengini alan yeni karşımın absorbans değeri ölçülür. Elde edilen yüksek absorbans değeri aynı zamanda yüksek indirgeme kapasitesine göstermektedir. Rheum özütlerinin $100 \mu \mathrm{L}$ 'sine, $250 \mu \mathrm{L}$ fosfat tamponu $(0.2 \mathrm{M} \mathrm{pH} \mathrm{6,6)}$ ve $250 \mu \mathrm{L} \% 1$ 'lik $\mathrm{K}_{3} \mathrm{Fe}(\mathrm{CN})_{6}$ eklenmiştir. Reaksiyon karışımı $50^{\circ} \mathrm{C}$ 'de 20 dak bekletilmiş ve $250 \mu \mathrm{L}$ \%10'luk TCA eklenmiş ve 2500 rpm'de 10 dak santrifüj edildikten sonra $250 \mu \mathrm{L}$ alınan örneklere eşit hacimde saf su ve $50 \mu \mathrm{L} \% 0,1$ 'lik $\mathrm{FeCl}_{3}$ çözeltisi ilave edilmiştir. Reaksiyon karışımına $1650 \mathrm{~mL}$ saf su eklenmiştir ve reaksiyon karışımlarının absorbansı 700 nm'de okutulmuştur. Standart olarak BHA çözeltisi (Bütilhidroksi anisol) kullanılmıştır. 
Süperoksit radikali giderme aktivitesi: Süperoksit anyonu giderme aktivitesi Nishikimi ve ark. (1972) metoduna göre belirlenmiştir. NADH/PMS/O $\mathrm{O}_{2}$ sistemi ile üretilen süperoksit radikali sarı renkli NBT'yi mavi-mor renkli formazon türevine indirgemektedir. $1 \mathrm{~mL} 156 \mu \mathrm{M}$ NBT $(0.1 \mathrm{M}$ fosfat tamponunda, $\mathrm{pH}$ 7.4) ve $1 \mathrm{~mL} 468 \mu \mathrm{M}$ NADH (0.1 M fosfat tamponunda, $\mathrm{pH}$ 7.4) karışımlarına 1 $\mathrm{mL}$ değişik konsantrasyonlarda hazırlanan bitki özütleri veya $1 \mathrm{~mL}$ standart BHA çözeltisi (50-400 $\mu \mathrm{g} / \mathrm{mL}$ ) ilave edilmiştir. Reaksiyon çözeltisine $100 \mu \mathrm{L} 60 \mu \mathrm{M}$ PMS çözeltisi ( $0.1 \mathrm{M}$ fosfat tamponu pH 7.4) eklendikten sonra $25^{\circ} \mathrm{C}^{\prime}$ de 5 dak inkübasyon sonunda örnekler spektrofotometrede 560 nm'de okutulmuştur. Aynı deney koşullarında $1 \mathrm{~mL}$ su kullanılarak kontrol çalışılmıştır. Aşağıdaki formüle göre özütlerin antioksidan aktiviteleri belirlenmiştir.

\% Süperoksit Radikali Giderme Aktivitesi $=((560$ nm'de Kontrol Absorbansı -560 nm’de Örnek Absorbans1)/560 nm'de Kontrol Absorbans1) x 100

\subsection{Antibakteriyel Analizler}

Antimikrobiyal analizler Kirby-Bauer disk difüzyon yöntemi kullanılarak gerçekleştirilmiştir (Bauer ve ark., 1966). Mikroorganizmaların bir gecelik kültürlerinin yoğunluğu steril fizyolojik tuzlu ile 0.5 MacFarland standart bulanıklığa ayarlanmıştır. Mueller Hinton Agar besiyeri yüzeyine steril eküvyon çubuğu ile 0.5 MacFarland bulanıklığa ayarlanan kültürler inoküle edilmiştir. İnokülasyonu takiben $6 \mathrm{~mm}$ çaplı steril blank disklere her bir yayla muzu ekstrelerinden $20 \mu \mathrm{L}$ emdirilip steril penset yardımı ile agar yüzeyine yerleştirilmiştir. Test edilen her mikroorganizma türüne spesifik pozitif kontrol kullanılmıştır. Escherichia coli, Klebsiella pneumoniae ve Proteus spp. için Tetrasiklin (30 mcg/disk); Staphylococcus aureus için Metisilin (5 mcg/disk); Pseudomonas aeruginosa için Polimiksin B (300 unite/disk) kullanılmıştır. Negatif kontrol olarak kullanılmak üzere ise steril blank disklere $20 \mu \mathrm{L}$ metanol emdirilmiştir. Disklerin eşit aralıklarla yerleştirildiği plaklar $37^{\circ} \mathrm{C}$ 'de 12-24 saat inkübe edilmiştir. İnkübasyon süresini takiben disklerin etrafinda bakterilerin üremediği şeffaf zonların varlığı incelenmiştir. Tüm antimikrobiyal analizler üç tekrarlı yürütülmüştür.

\section{5. İstatistiksel Analiz}

Analiz sonuçları, SPSS 22.0 paket programı kullanılarak varyans analizine tabi tutulmuş ve önemli bulunan farklılıklar Tukey çoklu karşılaştırma testine göre belirlenmiştir $(\mathrm{p}<0.05)$. 


\section{Araştırma Bulguları}

Çözücülerin polaritesine bağlı olarak özütlerin verimi değişmekle birlikte, en yüksek ekstraksiyon verimi metanol ekstratında \%25.3 olarak belirlenmiştir. Etil asetat ve saf su kullanılarak yapılan uygulamalar sonucunda elde edilen \% verim 18 ve 20'dir. En düşük ekstraksiyon verimi ise hekzanda \%10 olarak hesaplanmıştır. Bitkilerdeki biyoaktif bileşiklerin hidrofobik özelliklerinden dolayı metanol ve saf su gibi polaritesi yüksek çözücülerin kullanıldığı çalışmalarda yüksek verim sonuçları elde edilmektedir. 10-100 mg/mL konsantrasyonlardaki özütlerin toplam fenolik madde miktarı mg GAE/g cinsinden Tablo 1'de verilmiştir.

Tablo 1. $R$. ribes özütlerinin toplam fenolik içerikleri (mg GAE/g ekstre)

\begin{tabular}{|c|c|c|c|c|}
\hline Konsantrasyon & Etil Asetat & Hekzan & Metanol & Saf su \\
\hline $10 \mathrm{mg} / \mathrm{mL}$ & $0.24 \pm 0.01^{\mathrm{c}}$ & $0.12 \pm 0.00^{\mathrm{e}}$ & $0.48 \pm 0.00^{\mathrm{d}}$ & $0.37 \pm 0.01^{\mathrm{c}}$ \\
\hline $25 \mathrm{mg} / \mathrm{mL}$ & $0.34 \pm 0.01^{b c}$ & $0.17 \pm 0.00^{\mathrm{d}}$ & $0.60 \pm 0.02^{\mathrm{c}}$ & $0.53 \pm 0.02^{b}$ \\
\hline $50 \mathrm{mg} / \mathrm{mL}$ & $0.42 \pm 0.00^{\mathrm{bc}}$ & $0.25 \pm 0.01^{\mathrm{c}}$ & $0.64 \pm 0.03^{\mathrm{c}}$ & $0.62 \pm 0.01^{\mathrm{ab}}$ \\
\hline $75 \mathrm{mg} / \mathrm{mL}$ & $0.60 \pm 0.02^{\mathrm{ab}}$ & $0.38 \pm 0.00^{\mathrm{b}}$ & $0.72 \pm 0.01^{\mathrm{b}}$ & $0.72 \pm 0.00^{\mathrm{a}}$ \\
\hline $100 \mathrm{mg} / \mathrm{mL}$ & $0.73 \pm 0.03^{\mathrm{a}}$ & $0.48 \pm 0.00^{\mathrm{a}}$ & $0.80 \pm 0.00^{\mathrm{a}}$ & $0.73 \pm 0.01^{\mathrm{a}}$ \\
\hline
\end{tabular}

*(Gösterilen veriler $n=3$ 'ün ortalama değerleridir. Grafikte farklı simgeler (a-e, a-d ve a-c) ile ifade edilen değerler arasındaki fark önemli bulunmuştur $(\mathrm{p}<0.05))$.

Fenolik maddelerin alt grubu olan flavonoidler, oksidanlara bir hidrojen aktararak etkisiz hale getiren antioksidan bileşiklerdir. $\mathrm{Bu}$ etki oksidan bileşiklerin baskılanma etkisi olarak değerlendirilmektedir (Memişoğlu, 2005). R. ribes özütlerindeki toplam flavonoid miktarı Tablo 2'de verilmiştir.

Tablo 2. $R$. ribes özütlerinin toplam flavonoid içerikleri (mg RE/g ekstre)

\begin{tabular}{|c|c|c|c|c|}
\hline Konsantrasyon & Etil Asetat & Hekzan & Metanol & Saf su \\
\hline $10 \mathrm{mg} / \mathrm{mL}$ & $0.059 \pm 0.00^{\mathrm{e}}$ & $0.058 \pm 0.00^{\mathrm{c}}$ & $0.061 \pm 0.00^{\mathrm{e}}$ & $0.062 \pm 0.00^{\mathrm{d}}$ \\
\hline $25 \mathrm{mg} / \mathrm{mL}$ & $0.126 \pm 0.00^{\mathrm{d}}$ & $0.061 \pm 0.00^{b c}$ & $0.108 \pm 0.01^{\mathrm{d}}$ & $0.075 \pm 0.00^{\mathrm{d}}$ \\
\hline $50 \mathrm{mg} / \mathrm{mL}$ & $0.183 \pm 0.01^{\mathrm{c}}$ & $0.069 \pm 0.01^{b}$ & $0.141 \pm 0.00^{\mathrm{c}}$ & $0.102 \pm 0.00^{c}$ \\
\hline $75 \mathrm{mg} / \mathrm{mL}$ & $0.219 \pm 0.01^{\mathrm{b}}$ & $0.080 \pm 0.00^{\mathrm{a}}$ & $0.209 \pm 0.00^{\mathrm{b}}$ & $0.129 \pm 0.00^{\mathrm{b}}$ \\
\hline $100 \mathrm{mg} / \mathrm{mL}$ & $0.254 \pm 0.00^{\mathrm{a}}$ & $0.084 \pm 0.00^{\mathrm{a}}$ & $0.321 \pm 0.00^{\mathrm{a}}$ & $0.174 \pm 0.02^{\mathrm{a}}$ \\
\hline
\end{tabular}

*(Gösterilen veriler $\mathrm{n}=3$ 'ün ortalama değerleridir. Grafikte farklı simgeler (a-e, a-d ve a-c) ile ifade edilen değerler arasındaki fark önemli bulunmuştur $(\mathrm{p}<0.05))$.

Özütlerin konsantrasyon oranı arttıkça toplam fenolik ve flavonoid madde içeriklerinin de arttığ1 gözlenmektedir. $R$. ribes özütlerindeki toplam fenolik madde içerikleri $0.12 \pm 0.00^{\mathrm{e}}$ ve $0.80 \pm 0.00^{\mathrm{a}} \mathrm{mg} \mathrm{GAE} / \mathrm{g}$ ekstre aralığında belirlenmiştir. Toplam flavonoid içerikleri ise $0.058 \pm 0.00^{\mathrm{c}}$ ve $0.321 \pm 0.00^{\mathrm{a}} \mathrm{mg} \mathrm{RE} / \mathrm{g}$ ekstre olarak hesaplanmıştır. Toplam fenolik ve flavonoid madde miktarları, Tukey çoklu değerlendirme testine göre karşılaştırıldığında ortalamalar arasındaki gözlenen fark önemli bulunmuştur. Konsantrasyona bağlı en yüksek fenolik ve flavonoid madde içerikleri metanolik özütte gözlenmekte olup, $100 \mathrm{mg} / \mathrm{mL}$ konsantrasyondaki fenolik madde içeriği $0.80 \pm 0.00^{\mathrm{a}}$ 
$\mathrm{mg} \mathrm{GAE} / \mathrm{g}$ ve flavonoid içerik ise $0.321 \pm 0.00^{\mathrm{a}} \mathrm{mg} \mathrm{RE} / \mathrm{g}$ olarak hesaplanmıştır. En düşük fitokimyasal içeriğe hekzan özütünde rastlanmıştır.

Farklı konsantrasyonlardaki $R$. ribes özütlerinin ve standart antioksidanın (BHT) \% inhibisyon cinsinden DPPH· radikal süpürme aktiviteleri ve IC50 dozu Tablo 3 ’te verilmiştir.

Tablo 3. $R$. ribes özütlerinin ve BHT’nin DPPH· süpürme aktivitesi (\%) ve IC50 dozu

\begin{tabular}{ccccccc}
\hline Özütler & $\mathbf{1 0} \mathbf{~ m g} / \mathbf{m L}$ & $\mathbf{2 5} \mathbf{~ m g} / \mathbf{m L}$ & $\mathbf{5 0 ~} \mathbf{~ g} / \mathbf{m L}$ & $\mathbf{7 5} \mathbf{~ m g} / \mathbf{m L}$ & $\mathbf{1 0 0} \mathbf{~ m g} / \mathbf{m L}$ & $\begin{array}{c}\text { IC50 dozu } \\
(\mathbf{m g} / \mathbf{m L})\end{array}$ \\
\hline Etil Asetat & $45.03 \pm 0.00^{\mathrm{e}}$ & $58.29 \pm 0.00^{\mathrm{d}}$ & $68.89 \pm 0.01^{\mathrm{c}}$ & $82.59 \pm 0.01^{\mathrm{b}}$ & $86.86 \pm 0.00^{\mathrm{a}}$ & 12.47 \\
Hekzan & $20.03 \pm 0.51^{\mathrm{e}}$ & $33.10 \pm 0.06^{\mathrm{d}}$ & $49.23 \pm 0.64^{\mathrm{c}}$ & $61.61 \pm 0.13^{\mathrm{b}}$ & $77.61 \pm 0.57^{\mathrm{a}}$ & 54.71 \\
Metanol & $46.00 \pm 0.06^{\mathrm{e}}$ & $60.20 \pm 0.13^{\mathrm{d}}$ & $70.00 \pm 0.32^{\mathrm{c}}$ & $86.00 \pm 0.01^{\mathrm{b}}$ & $91.10 \pm 0.51^{\mathrm{a}}$ & 10.50 \\
Saf su & $30.80 \pm 0.1^{\mathrm{d}}$ & $39.03 \pm 0.51^{\mathrm{cd}}$ & $53.38 \pm 0.06^{\mathrm{bc}}$ & $69.13 \pm 0.38^{\mathrm{ab}}$ & $84.82 \pm 0.13^{\mathrm{a}}$ & 42.97 \\
Standart & $200 \mu \mathrm{g} / \mathrm{mL}$ & $400 \mu \mathrm{g} / \mathrm{mL}$ & $600 \mu \mathrm{g} / \mathrm{mL}$ & $800 \mu \mathrm{g} / \mathrm{mL}^{\mathrm{a}}$ & $1000 \mu \mathrm{g} / \mathrm{mL}$ & 0.58 \\
BHT & $26.29 \pm 0.18^{\mathrm{e}}$ & $42.53 \pm 1.31^{\mathrm{d}}$ & $51.99 \pm 0.54^{\mathrm{c}}$ & $63.53 \pm 1.61^{\mathrm{b}}$ & $70.67 \pm 0.30^{\mathrm{a}}$ & \\
\hline
\end{tabular}

*(Gösterilen veriler $n=3$ 'ün ortalama değerleridir. Grafikte farklı simgeler (a-e ve a-d) ile ifade edilen değerler arasındaki fark önemli bulunmuştur $(\mathrm{p}<0.05))$.

R. ribes özütlerindeki toplam fenolik ve flavonoid içeriğin yüksek olduğu metanolik ekstraktta en yüksek DPPH· giderme aktivitesi $100 \mathrm{mg} / \mathrm{mL}$ konsantrasyonda $\% 91.10 \pm 0.51^{\text {a }}$ olarak belirlenmiştir. Özütün IC50 dozu $10.50 \mathrm{mg} / \mathrm{mL}$ 'dir. \% inhibisyonun en yüksek olduğu metanolik ekstraktın, DPPH·'ın \%50'sini inhibe eden dozu düşüktür. $R$. ribes'in etil asetat, hekzan, metanol ve saf su ekstraktlarının $100 \mathrm{mg} / \mathrm{mL}$ 'lik konsantrasyonlarında sırasıyla $\% 86.86 \pm 0.00^{\mathrm{a}}, 77.61 \pm 0.57^{\mathrm{a}}$, $91.10 \pm 0.51^{\mathrm{a}}$ ve $84.82 \pm 0.13^{\mathrm{a}}$ radikal giderme aktivitesi gözlenmiştir. Standart olarak BHT kullanılan test sisteminde $1000 \mu \mathrm{g} / \mathrm{mL}$ konsantrasyonda $\% 70.67 \pm 0.30^{\mathrm{a}}$ inhibisyon gözlenmiş ve IC50 dozu 0.58 $\mathrm{mg} / \mathrm{mL}$ olarak tespit edilmiştir.

$R$. ribes'in kök ve gövde kısımlarının metanol ve kloroform özütlerinin incelendiği literatürde, çalışmamıza benzer şekilde en yüksek fenolik içerik (35.71 $\pm 1.23 \mu \mathrm{g}$ PEs/mg) gövde metanol özütünde belirlenmiştir. Çalışmamıza benzer nitelikte fenolik içeriğinin en yüksek olduğu gövde metanol ekstraktında yükssek DPPH· inhibisyonu kaydedilmiştir (Öztürk ve ark., 2007). Bingöl'den toplanan yenilebilir yabani sebzelerden $R$. ribes L.'nin aseton; saf su; asetik asit (70:29.5:0.5 v/v/v)

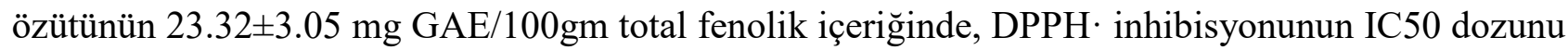
32.66 \pm 1.45 olarak tespit etmişlerdir (Samancıoğlu ve ark., 2016). Bu IC50 dozu çalışmamızda metanol özütünde hesaplanan $(10.50 \mathrm{mg} / \mathrm{mL})$ değerden oldukça yüksektir.

Çalışmamızda polar çözücüler arasındaki en yüksek IC50 dozu (42.97 mg/mL) saf su özütlerinde rastlanmıştır. Benzer şekilde, $R$. ribes L.'nin kök sulu ve etanol özütlerinin incelendiği çalışmada, yüksek fenolik ve flavonoid içeriği gözlenen etanol ekstraktının (4.73 $\mu \mathrm{g} / \mathrm{mL})$ IC50 dozu su ekstraktına (25.62 $\mu \mathrm{g} / \mathrm{mL})$ göre düşük bulunmuştur (Khalida ve ark., 2014).

Meral (2017), çalışmamızın sonuçlarına benzer olarak fenolik madde miktarı yüksek güneşte kurutularak hazırlanan özütte en yüksek DPPH· inhibisyonu (\%52-91) kaydedilmiştir. Mohammed ve ark. (2018) tarafından $R$. ribes' in kök ve gövde etil asetat, hekzan ve metanol özütlerinde en yüksek 
fenolik içerik etil asetat özütlerinde $88.28 \pm 0.40 \mu \mathrm{g}$ GAE/mg olarak belirlenirken en yüksek flavonoid

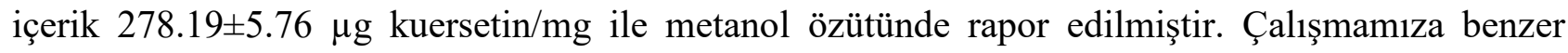
şekilde en düşük total fenolik (11.72 $\pm 0.10 \mu \mathrm{g}$ GAE/mg) ve flavonoid $(10.23 \pm 1.58 \mu \mathrm{g}$ quercetin E/mg) içerik hekzan özütünde tespit edilmiştir.

Y1ldırım ve ark. (2015) R. ribes ’in tohum ve meyvesinin metanolik özütlerinin antioksidan aktivite analizlerinde çalışmamızı destekler nitelikte konsantrasyon arttıkça ekstraktların \% radikal süpürme aktivitesinin de arttığı tespit edilmiştir. En yüksek radikal giderme aktivitesi meyve özütünde \%78 olarak belirlenmiş olup, çalışmamızda kaydedilen 75 ve 100 mg/mL konsantrasyonda gövde metanol özütlerinin antioksidan aktivitesinden oldukça düşüktür $\left(86.00 \pm 0.01^{\mathrm{b}}\right.$ ve $\left.91.10 \pm 0.51^{\mathrm{a}}\right)$.

Çalışmamıza benzer olarak Mohammed ve ark. (2018), etil asetat, hekzan ve metanol kök ve

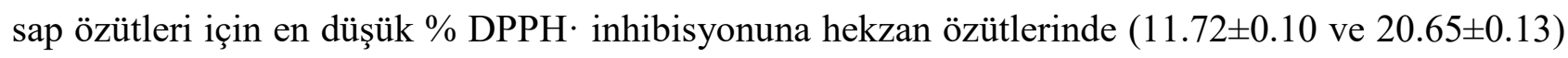
rastlamışlardır. Nemat Shahi ve ark. (2016) tarafından $R$. ribes metanolik özütünün en yüksek DPPH· inhibisyonu $300 \mathrm{mg} / \mathrm{L}$ konsantrasyonda ortalama \%90 olarak tespit edilmiştir. Bu inhibisyon çalışmamızda belirlenen $100 \mathrm{mg} / \mathrm{mL}$ konsantrasyonda elde edilen $\% 91.10 \pm 0.51^{\mathrm{a}}$ 'den oldukça düşüktür.

Çalışmamızda elde edilen veriler gibi, $300 \mu \mathrm{g}$ R. ribes içeren ekstraktların DPPH inhibisyon analizinde en düşük absorbans değeri polar çözücülerde belirlenmiştir (Oktay ve ark., 2007).

Özütlerin $\mathrm{Fe}^{+2}$ iyonlarını şelatlama analizleri, Tukey çoklu değerlendirme testine göre karşılaştırıldığında ortalamalar arasındaki gözlenen fark önemli bulunmuştur (Tablo 4).

Tablo 4. $R$. ribes özütlerinin Fe Şelatlama aktivitesi (\%)

\begin{tabular}{cccccc}
\hline & $\mathbf{1 0} \mathbf{~ m g} / \mathbf{m L}$ & $\mathbf{2 5} \mathbf{~ m g} / \mathbf{m L}$ & $\mathbf{5 0} \mathbf{~ m g} / \mathbf{m L}$ & $\mathbf{7 5} \mathbf{~ m g} / \mathbf{m L}$ & $\mathbf{1 0 0} \mathbf{~ m g} / \mathbf{m L}$ \\
\hline Etil Asetat & $9.17 \pm 0.28^{\mathrm{e}}$ & $16.39 \pm 0.83^{\mathrm{d}}$ & $17.50 \pm 0.28^{\mathrm{c}}$ & $24.44 \pm 1.11^{\mathrm{b}}$ & $31.67 \pm 1.11^{\mathrm{a}}$ \\
Hekzan & $4.44 \pm 0.56^{\mathrm{e}}$ & $11.90 \pm 1.40^{\mathrm{d}}$ & $16.40 \pm 0.80^{\mathrm{c}}$ & $22.50 \pm 1.90^{\mathrm{b}}$ & $27.80 \pm 0.60^{\mathrm{a}}$ \\
Metanol & $25.60 \pm 1.10^{\mathrm{c}}$ & $29.70 \pm 1.40^{\mathrm{c}}$ & $36.40 \pm 1.40^{\mathrm{b}}$ & $40.30 \pm 1.40^{\mathrm{b}}$ & $49.70 \pm 3.10^{\mathrm{a}}$ \\
Saf su & $9.20 \pm 0.80^{\mathrm{e}}$ & $19.44 \pm 0.56^{\mathrm{d}}$ & $25.00 \pm 0.56^{\mathrm{c}}$ & $30.56 \pm 2.22^{\mathrm{b}}$ & $40.83 \pm 1.94^{\mathrm{a}}$ \\
Standart & $50 \mu \mathrm{g} / \mathrm{mL}$ & $100 \mu \mathrm{g} / \mathrm{mL}$ & $150 \mu \mathrm{g} / \mathrm{mL}$ & $200 \mu \mathrm{g} / \mathrm{mL}$ & $250 \mu \mathrm{g} / \mathrm{mL}$ \\
EDTA & $80.16 \pm 1.34^{\mathrm{b}}$ & $93.59 \pm 0.83^{\mathrm{a}}$ & $94.42 \pm 0.00^{\mathrm{a}}$ & $94.83 \pm 0.00^{\mathrm{a}}$ & $94.73 \pm 0.10^{\mathrm{a}}$ \\
\hline
\end{tabular}

*(Gösterilen veriler $\mathrm{n}=3$ 'ün ortalama değerleridir. Grafikte farklı simgeler (a-e, $a-b$ ve a-c) ile ifade edilen değerler arasındaki fark önemli bulunmuştur $(\mathrm{p}<0.05))$.

$R$. ribes özütlerinin $\mathrm{Fe}^{+2}$ iyonlarını şelatlama aktivitesi $\% 4.44 \pm 0.56^{\mathrm{e}}$ ve $49.70 \pm 3.10^{\mathrm{a}}$ aralığındadır. DPPH· radikali giderme aktivitesi sonuçlarımıza benzer şekilde en düşük metal şelatlama aktivitesi hekzan özütünde $\left(4.44 \pm 0.56^{\mathrm{e}}\right)$ belirlenmiştir. $100 \mathrm{mg} / \mathrm{mL}$ konsantrasyondaki etil asetat, hekzan, metanol ve saf su özütlerinin $\mathrm{Fe}^{+2}$ iyonlarını şelatlama aktivitesi sırasıyla $\% 31.67 \pm 1.11,27.80 \pm 0.60,49.70 \pm 3.10$ ve $40.83 \pm 1.94$ olarak tespit edilmiştir.

50-250 $\mu \mathrm{g} / \mathrm{mL}$ konsantrasyonda EDTA kullanılan test sisteminde metal şelatlama aktivitesi $\% 80.16 \pm 1.34^{\mathrm{b}}$ ve $94.73 \pm 0.10^{\mathrm{a}}$ olarak hesaplanmışır. Test edilen $R$. ribes ekstraktlarının $\mathrm{Fe}^{+2}$ iyonlarını şelatlama aktivitesi EDTA ile karşılaştırıldığında oldukça düşüktür. 
Tanrıkurt ve ark. (2013), Diyarbakır yerel marketlerden temin edilen $R$. ribes gövde kısımlarından sulu özütler hazırlamışlar ve ortalama olarak EDTA'dan 90 kat daha düşük metal şelatlama aktivitesi saptamışlardır. Öztürk ve ark. (2007), $R$. ribes'in kök ve gövde kısımlarının metanol ve kloroform özütlerinin metal şelatlama aktivitesini inceledikleri çalışmada, sonuçlarımıza benzer şekilde özütlerinin konsantrasyonu arttıkça şelatlama aktivitesinin de arttığını saptamışlardır. En yüksek metal şelatlama aktivitesi metanol gövde özütünde $\% 93.71 \pm 0.80$ olarak tespit edilmiştir. Çalışmamızda elde edilen en yüksek şelatlama aktivitesinden $\left(\% 49.70 \pm 3.10^{\mathrm{a}}\right)$ oldukça yüksektir.

Özütlerin indirgeme kapasitesi analiz sonuçları Tablo 5'te verilmiştir.

Tablo 5. $R$. ribes özütlerinin indirgeme kapasitesi tayini (abs.)

\begin{tabular}{cccccc}
\hline & $\mathbf{1 0} \mathbf{~} \mathbf{~ g} / \mathbf{m L}$ & $\mathbf{2 5} \mathbf{~ m g} / \mathbf{m L}$ & $\mathbf{5 0 ~} \mathbf{~ m g} / \mathbf{m L}$ & $\mathbf{7 5 ~} \mathbf{~ g} / \mathbf{m L}$ & $\mathbf{1 0 0} \mathbf{~ m g} / \mathbf{m L}$ \\
\hline Etil Asetat & $0.07 \pm 0.01^{\mathrm{d}}$ & $0.09 \pm 0.00^{\mathrm{c}}$ & $0.11 \pm 0.00^{\mathrm{b}}$ & $0.11 \pm 0.00^{\mathrm{b}}$ & $0.13 \pm 0.01^{\mathrm{a}}$ \\
Hekzan & $0.07 \pm 0.00^{\mathrm{e}}$ & $0.09 \pm 0.00^{\mathrm{d}}$ & $0.11 \pm 0.00^{\mathrm{c}}$ & $0.10 \pm 0.00^{\mathrm{b}}$ & $0.12 \pm 0.00^{\mathrm{a}}$ \\
Metanol & $0.12 \pm 0.00^{\mathrm{e}}$ & $0.13 \pm 0.00^{\mathrm{d}}$ & $0.15 \pm 0.00^{\mathrm{c}}$ & $0.17 \pm 0.00^{\mathrm{b}}$ & $0.19 \pm 0.00^{\mathrm{a}}$ \\
Saf su & $0.09 \pm 0.00^{\mathrm{e}}$ & $0.11 \pm 0.00^{\mathrm{d}}$ & $0.12 \pm 0.00^{\mathrm{c}}$ & $0.13 \pm 0.01^{\mathrm{b}}$ & $0.14 \pm 0.00^{\mathrm{a}}$ \\
Standart & $20 \mu \mathrm{g} / \mathrm{mL}$ & $50 \mu \mathrm{g} / \mathrm{mL}$ & $100 \mu \mathrm{g} / \mathrm{mL}$ & $200 \mu \mathrm{g} / \mathrm{mL}$ & $400 \mu \mathrm{g} / \mathrm{mL}$ \\
BHA & $0.22 \pm 0.01^{\mathrm{c}}$ & $0.24 \pm 0.01^{\mathrm{c}}$ & $0.25 \pm 0.02^{\mathrm{c}}$ & $0.32 \pm 0.03^{\mathrm{b}}$ & $0.51 \pm 0.01^{\mathrm{a}}$ \\
\hline
\end{tabular}

*(Gösterilen veriler $\mathrm{n}=3$ 'ün ortalama değerleridir. Grafikte farklı simgeler (a-e, a-d ve a-c) ile ifade edilen değerler arasındaki fark önemli bulunmuştur $(\mathrm{p}<0.05))$.

R. ribes özütlerinin $\mathrm{Fe}^{+3}$ 'ü indirgeme kapasitelerinin standartlara kıyasla oldukça düşük olduğu belirlenmiştir. Özütlerin indirgeme kapasiteleri $0.07 \pm 0.00$ ve $0.19 \pm 0.00$ aralığındadır. En yüksek indirgeme aktivitesinin gözlendiği $100 \mathrm{mg} / \mathrm{mL}$ konsantrasyonda metanol özütünün aktivitesi $0.19 \pm 0.00$ 'dır. $\mathrm{Bu}$ absorbans değeri standart olarak kullanılan BHA'nın $20 \mu \mathrm{g} / \mathrm{mL}$ ve diğer konsantrasyonlardaki indirgeyici güçten oldukça düşüktür.

Oktay ve ark. (2007), Erzurum ilinden temin edilen ışgının (R. ribes) farklı kısımlarından elde edilen eter, etanol ve saf su özütlerinden sadece etanol ekstresinde indirgeme kapasitesini belirlemişlerdir. Fakat bu antioksidan aktivite istatiksel olarak anlamsız bulunmuştur. Tanrıkurt ve ark. (2013), Diyarbakır'dan temin edilen $R$. ribes sulu gövde özütlerinde $250 \mu \mathrm{g} / \mathrm{mL}$ konsantrasyonda indirgeme kapasitesini $0.46 \pm 0.074$ olarak tespit etmişlerdir. Çalışmamızı destekler nitelikte yüksek indirgeme kapasitesi $250 \mu \mathrm{g} / \mathrm{mL}$ konsantrasyonda yüksek fenolik ve flavonoid içerikle ilişkilendirilmiştir.

Özütlerin süperoksit radikali giderme aktivitesi in vitro koşullarda $\mathrm{PMS} / \mathrm{NADH} / \mathrm{O}_{2}$ sisteminde süperoksit radikali oluşturularak çalışılmış ve bu radikali etkisizleştirebilme kapasiteleri belirlenmiştir (Tablo 6). 
Tablo 6. $R$. ribes özütlerinin süperoksit radikali giderme aktivitesi (\%)

\begin{tabular}{cccccc}
\hline & $\mathbf{1 0} \mathbf{~ m g} / \mathbf{m L}$ & $\mathbf{2 5} \mathbf{~ m g} / \mathbf{m L}$ & $\mathbf{5 0} \mathbf{~ m g} / \mathbf{m L}$ & $\mathbf{7 5 ~} \mathbf{~ g} / \mathbf{m L}$ & $\mathbf{1 0 0} \mathbf{~ m g} / \mathbf{m L}$ \\
\hline Etil Asetat & $14.40 \pm 0.80^{\mathrm{c}}$ & $22.00 \pm 2.80^{\mathrm{b}}$ & $25.60 \pm 1.60^{\mathrm{bc}}$ & $28.00 \pm 2.40^{\mathrm{ab}}$ & $32.00 \pm 2.40^{\mathrm{a}}$ \\
Hekzan & $12.00 \pm 2.40^{\mathrm{d}}$ & $18.40 \pm 0.80^{\mathrm{c}}$ & $24.80 \pm 0.80^{\mathrm{b}}$ & $28.40 \pm 0.40^{\mathrm{ab}}$ & $32.00 \pm 1.60^{\mathrm{a}}$ \\
Metanol & $18.80 \pm 0.40^{\mathrm{d}}$ & $27.20 \pm 3.20^{\mathrm{c}}$ & $31.60 \pm 4.40^{\mathrm{ab}}$ & $36.40 \pm 2.80^{\mathrm{a}}$ & $39.20 \pm 2.40^{\mathrm{a}}$ \\
Saf su & $12.80 \pm 0.80^{\mathrm{d}}$ & $24.40 \pm 0.40^{\mathrm{c}}$ & $32.00 \pm 1.60^{\mathrm{b}}$ & $40.00 \pm 0.80^{\mathrm{a}}$ & $40.00 \pm 2.40^{\mathrm{a}}$ \\
Standart & $50 \mu \mathrm{g} / \mathrm{mL}$ & $100 \mu \mathrm{g} / \mathrm{mL}$ & $200 \mu \mathrm{g} / \mathrm{mL}$ & $300 \mu \mathrm{g} / \mathrm{mL}$ & $500 \mu \mathrm{g} / \mathrm{mL}$ \\
BHA & $11.50 \pm 0.26^{\mathrm{e}}$ & $17.10 \pm 0.77^{\mathrm{d}}$ & $22.20 \pm 0.77^{\mathrm{c}}$ & $26.30 \pm 0.26^{\mathrm{b}}$ & $28.80 \pm 0.77^{\mathrm{a}}$ \\
\hline
\end{tabular}

*(Gösterilen veriler $\mathrm{n}=3$ 'ün ortalama değerleridir. Grafikte farklı simgeler (a-e, a-d ve a-c) ile ifade edilen değerler arasındaki fark önemli bulunmuştur $(\mathrm{p}<0.05))$.

50-500 $\mu \mathrm{g} / \mathrm{mL}$ konsantrasyonda BHA'nin süperoksit anyonu giderme aktivitesi $\% 11.50 \pm 0.26^{\mathrm{e}}$ ve $28.80 \pm 0.77^{\mathrm{a}}$ aralığındadır. Ekstraktların süperoksit anyonu giderme aktiviteleri $\mu \mathrm{g} / \mathrm{mL}$ konsantrasyonda test edilen BHA standardından düşüktür.

Polarite indeksi en düşük çözücü hekzan kullanılarak hazırlanmış özütlerin süperoksit anyonu giderme aktivitesi sonuçları, diğer antioksidan aktivite testlerine kıyasla diğer çözücülere yakın \% inhibisyon değerleri göstermiştir. Özütlerin konsantrasyon artış1 ile süperoksit anyonu giderme aktivitesindeki artışı test edilen tüm konsantrasyonlarda doğru orantılı değildir. Bu sebeple diğer antioksidan aktivite analizlerine karşın, özütlerin süperoksit radikali oluşum inhibisyon değerlerinin konsantrasyona bağlı olmadıkları saptanmıştır.

Tanrıkurt ve ark. (2013), R. ribes'in sulu özütlerinin farklı konsantrasyonlarda süperoksit anyonu giderme aktivitesini test etmişler ve $500 \mu \mathrm{g} / \mathrm{mL}$ konsantrasyonda $\% 31.21 \pm 1.00$ olarak saptamışlardır. $\mathrm{Bu}$, çalışmamızda elde edilen en yüksek aktivitenin gözlendiği $\left(\% 39.20 \pm 2.40^{\mathrm{a}}\right)$ metanol özütünün konsantrasyonundan $(100 \mathrm{mg} / \mathrm{mL})$ oldukça düşüktür. Oktay ve ark. (2007), $R$. ribes'in etanol, eter ve su özütlerinin en yüksek süperoksit giderme aktivitelerini kök eter $(87.01 \pm 0.21)$ ve etanol $(86.69 \pm 0.10)$ özütlerinde saptamışlardır. Çalışmamızdan farklı olarak polaritesi düşük çözücüde yüksek aktivite belirlenmiştir.

Negatif kontrol olarak konsantre metanol kullanılmış ve metanolün izolatlar üzerinde antibakteriyel aktivitesine rastlanmamıştır. $100 \mathrm{mg} / \mathrm{mL}$ konsantrasyonda $R$. ribes'in etil asetat, hekzan ve metanol özütlerinin test bakterileri üzerinde antibakteriyel aktivite gösteremediği belirlenmiştir. $R$. ribes' in saf su ekstraktının $100 \mathrm{mg} / \mathrm{mL}$ konsantrasyonda test bakterilerine karşı antibakteriyel aktivite gösterdiği gözlenmiştir. Saf su özütlerinin bakterilere karşı gösterdiği antibakteriyel aktivite $9.00 \pm 1.00$ ve $14.50 \pm 1.50 \mathrm{~mm}$ zon çapı aralığındadır. En yüksek inhibitör etki $14.50 \pm 1.50$ mm zon çapı ile S. aureus'a karşı gözlenmiştir (Şekil 1) 

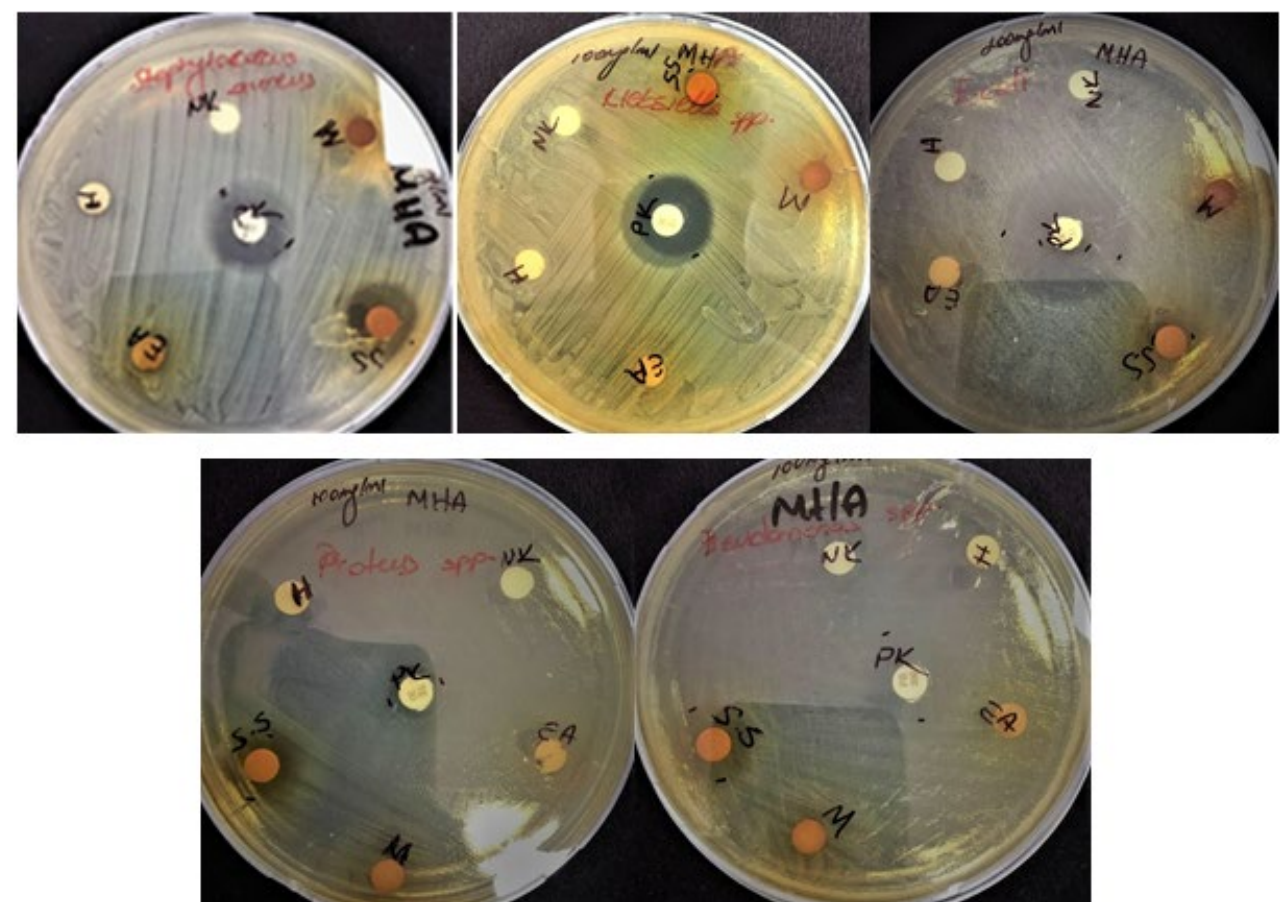

Şekil 1. Ekstraktların ve standart antibiyotiklerin test bakterilerine karşı antibakteriyel aktivitesi

$\mathrm{Bu}$ inhibisyon polarite indeksi yüksek saf su gibi çözücülerle hazırlanmış özütlerin içerdiği polifenol miktarının yüksekliği ile ilişkilendirilebilir. Gr negatif test bakterilerine karşı en yüksek inhibitör aktivite $12.00 \pm 2.00 \mathrm{~mm}$ zon çapı ile $P$. aeruginosa'ya karşı gözlenmiştir. Ancak bu antibakteriyel aktivite, $P$. aeruginosa'ya karşı standart Polimiksin B antibiyotiği için belirlenen $17.00 \pm 0.00 \mathrm{~mm}$ inhibitör etkiden daha zayıftır.

Saf su özütünün en yüksek antibakteriyel aktivite gösterdiği S. aureus'a karş1 25, 50 ve 75 $\mathrm{mg} / \mathrm{mL}$ test konsantrasyonlarının da inhibitör etkisi saptanmıştır. Konsantrasyona bağlı olarak inhibitör aktivitenin artış gösterdiği belirlenmiştir. 25, 50 ve $75 \mathrm{mg} / \mathrm{mL}$ konsantrasyonları için belirlenen inhibitör aktivite sırasıyla $8.60 \pm 0.40,10.00 \pm 1.00$ ve $11.50 \pm 0.50 \mathrm{~mm}$ olarak belirlenmiştir (Şekil 2).

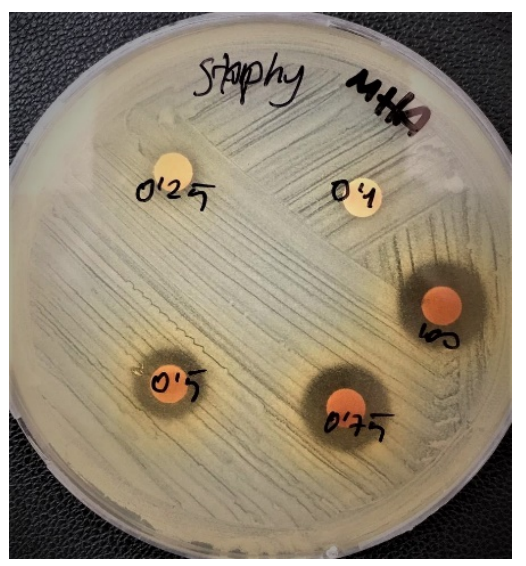

Şekil 2. $R$. ribes saf su ekstraktının S. aureus'a etkili olduğu konsantrasyonlar 
Sonuçlarımıza benzer şekilde literatürdeki çalışmalarda $R$. ribes bitkisinin farklı kısımlarının antibakteriyel aktivitesi gözlenmiş olup, bu inhibitör etki çözücü, test edilen mikroorganizma ve ekstraksiyon metotlarına bağlı olarak değişiklik göstermektedir.

Kosikowska ve ark. (2010) tarafından Rheum spp.'nin etanol özütünde çalışmamızı destekler nitelikte Gr pozitif bakteri Staphylococcus spp.'ye karşı Gr negatif bakterilerden (Escherichia coli, Klebsiella pneumoniae ve Proteus mirabilis) daha yüksek inhibitör etki gösterdiği belirlenmiştir. Sonuçlarımıza benzer şekilde $R$. ribes'in etanol ve sulu özütlerinde $E$. coli, S. aureus, P. aeruginosa ve $P$. mirabilis karşı geniş bir spektrumda antibakteriyel aktivitesi tespit edilmiştir (Khalida ve ark. 2014). Sonuçlarımızdan farklı olarak, Obaid ve ark. (2016), R. ribes metanolik özütünde 9.76-5000 $\mu \mathrm{g} / \mathrm{mL}$ konsantrasyonlarda $E$. coli üzerinde antibakteriyel aktivite saptamışlardır.

$R$. ribes ile yapılan farklı bir çalışmada (Tanış ve ark., 2010) standart suşlar üzerinde belirlenen 6-19 mm arasında inhibisyon, sonuçlarımızı desteklemektedir. $R$. ribes'in $25-75 \mathrm{mg} / \mathrm{mL}$ konsantrasyonda kök etanolik ve saf su özütlerinin E. coli, S. aureus, $P$. mirabilis ve $P$. aeruginosa' ya karşı güçlü antibakteriyel aktivite gözlenmiş olup (Khalida ve ark., 2014), bu sonuçlar su özütüne ilişkin sonuçlarımız ile uyumludur.

\section{Tartışma ve Sonuç}

$\mathrm{Bu}$ çalışma, Anadolu ve Ortadoğu'da yaygın olarak kullanılan yenilebilir ve tıbbi bitkilerden biri olan $R$. ribes'in antioksidan ve antimikrobiyal önemini ortaya koymuştur. Sonuçlarımıza göre, $R$. ribes özütlerinin serbest radikal hasarına karşı koruyucu ve yardımcı güvenli gıda ürünleri ve katkı maddelerinin geliştirilmesi için kullanılabilecektir. Bununla birlikte, daha ileriki çalışmalarda, özellikle $R$. ribes metanol özütlerinden antioksidan aktivite gösteren bileşenlerin tanımlanması ve in vivo antioksidan aktivite testlerinin yapılması gereklidir.

\section{Teşekkürler}

Bu çalışma 2019 yılında Kilis 7 Aralık Üniversitesi Fen Bilimleri Enstitüsünde yüksek lisans tezi olarak sunulmuş ve kabul edilmiştir.

\section{Yazarların Katkısı}

Tüm yazarlar çalışmaya eşit katkıda bulunmuştur. 


\section{Çıkar Çatışması Beyanı}

Yazarlar arasında herhangi bir çıkar çatışması bulunmamaktadır.

\section{Araştırma ve Yayın Etiği Beyanı}

Yapılan çalışmada araştırma ve yayın etiğine uyulmuştur.

\section{Kaynaklar}

Andiç, S., Tuncturk, Y., Ocak, E., and Kose, S., (2009). Some chemica characteristic of edible wild rhubarb species (Rheum ribes L.). Research Journal of Agriculture and Biological Sciences, 5(6), 973-977.

Bauer, A. W., Kirby, W. M., Sherris, J. C., and Turck, M., (1966). Antibiotic susceptibility testing by a standardized single disk method. American Journal of Clinical Pathology, 45(4), 493-496.

Blois, M. S., (1958). Antioxidant determinations by the use of a stable free radical. Nature, 26, 1199-1200.

Davis, P. H., (1967). Flora of Turkey and The Aegean Islands, Edinburg Universiyt Press

Dinis, T. C., Madeira, V. M., and Almeida, L. M., (1994). Action of phenolic derivates (acetoaminophen, salycilate and 5-aminosalycilate) as inhibitors of membrane lipid peroxidation and as peroxyl radical scavengers. Archives of Biochemistry and Biophysics, 315(1), 161-169.

Güvenç, İ., Kaya, Y., (1996). Erzurum'da sebze olarak değerlendirilen yöresel bazı bitkiler. Ankara Üniversitesi Ziraat Fakültesi Dergisi, 27(3): 369-374.

Khalida, K. A., Ehklass, M. T., and Saleh, R. S., (2014). Phenolic profile, antioxidant, and antibacterial effects of ethanol and aqueous extracts of Rheum ribes L. Roots, Der Pharmacia Lettre, 6(5), 201-205.

Kosikowska, U., Smolarz, H. D., and Malm, A., (2010). Antimicrobial activity and total content of polyphenols of Rheum L. species growing in Poland, Current Europan Journal of Biology, 5(6), 814-820.

Memişoğulları, R., 2005. Diyabette serbest radikallerin rolü ve antioksidanların etkisi. Düzce Tıp Fakültesi Dergisi 7(3): 30-39.

Meral, R., (2017). Farklı Sicaklık derecelerinin uşkun bitkisinin antioksidan aktivitesi ve fenolik profili üzerine etkisi. Yüzüncü Yll Üniversitesi Tarım Bilimleri Dergisi, 27(1), 88-94.

Mohammed, B., and Karim., J. K., (2010). Antitumoractivity of Rheum ribes and Thymus syriacus in male albino mice, Journal of Thi-Qar Science, 2(3), 2-11.

Mohammed, I. H., Kakey, E. S., and Farimani, M. M., (2018). In vitro evaluation of antioxidant activates for parts of rhubarb (Rheum ribes) and syrian mesquite (Prosopis farcta). International Conference on Pure and Applied Sciences (ICPAS 2018)

Nemat Shahi, M. M., Elhami Rad, A. H., Nemat Shahi, N., and Bakhsh Amin, M. R., (2016). Study of antioxidant activity and free radical scavenging power of Rheum ribes flower extract. Journal of Fundamental and Applied Sciences, 8(3), 1164-1174.

Nishikimi, M., Rao, Na., and Yagi, K., (1972). The occurance of superoxide anion in the reaction of reduced phenazine methosulfate and molecular oxygen. Biochemical and Biophysical Research Communications, 46(2), 849-854.

Obaida, H. H., Tawfeeqb, H. K., Zamel Khalafc, Z., and Shafeeq, Z. S., (2016). Inhibitory effect of rhizomes methanolic extracts of Rheum ribes and $\mathrm{TiO}_{2} \mathrm{NPs}$ on Escherichia coli. International Journal of Sciences: Basic and Applied Research (IJSBAR), 30(1), 262-275.

Oktay, M., Y1ldırım, A., Bilaloglu, V., and Gulcin I., (2007). Antioxidant activity of different parts of 1sgin (Rheum ribes L.), Asian Journal of Chemistry, 19(4), 3047-3055.

Oyaizu, M., (1986). Studies on product of browing reaction prepared from glucose amine. Japan of Nutrition, 44, 307-315.

Ozturk, M., Aydogmus Ozturk, F., Duru, M. E., and Topcu, G., (2007). Antioxidant activity of stem and root extracts of Rhubarb (Rheum ribes): An edible medicinal plant. Food Chemistry, 103(2), 623-630. 
Samancioglu, A., Sat, I. G., Yildirim, E., Ercisli, S., Jurikova, T., and Mlcek, T., (2016). Total phenolic and vitamin $\mathrm{C}$ content and antiradical activity evaluation of traditionally consumed wild edible vegetables from Turkey. Indian Journal of Traditional Knowledge, 15(2), 208-213.

Sharm, S., and Vig, P. A., (2013). Evaluation of in vitro antioxidant properties of methanol and aqueous extracts of Parkinsonia aculeata L. leaves. The Scientific World Journal, 2013. Article ID 604865

Stankovic, M. S., (2011). Total phenolic content,flavonoid concentration and antioxdant activity of Marrubium peregrinum L. extracts, Kragujevac Journal of Science. 33(2011), 63-72.

Tanis, H., Karcioğlu, L., Dıraz, E., ve Aygan, A., (2010). Kahramanmaras Bölgesinde Yetisen Isgin (Rheum ribes L.)'1n Antibakteriyal Aktivitesinin Belirlenmesi. KSÜ Doğa Bilimleri Dergisi, 13(2), 1-3.

Tanrikut, S. E., Ceken, B., Altas, S., Pirinccioglu, M., Kizil, G., and Kizil, M., (2013). DNA cleavage protecting activity and in vitro antioxidant potential of aqueous extract from fresh stems of Rheum ribes. Acta Alimentaria, 42(4), 461-472.

Tosun, F., and Akyuz Kizilay, C., (2003). Anthraquinones and flavanoids from Rheum ribes. Journal of Faculty Pharmacy Ankara, 32(1), 31-35.

Yildirim, I., Kutlu, T., and Takim, K., (2015). Comparison of antioxidant activity of Rheum ribes fruits and seed methanolic extracts against protein oxidation and lipid peroxidation. Pakistan Journal of Biological Sciences, 18(5), 232-239. 